\title{
MEDICAL EQUIPMENT SUPPLIER EVALUATION APPROACH BASED ON ANP, FUZZY TOPSIS AND SUPER DECISION
}

\author{
Xi Chen ${ }^{1} \cdot$ Yuan Luo $^{2}$ \\ Xi Chen \\ chenxivip710@126.com \\ Yuan Luo \\ 18710895707@163.com \\ ${ }^{12}$ School of Economics \& Management, Xidian University, Xi'an 710071, China
}

\begin{abstract}
Increasing demand of medical equipment brings both opportunities and challenges for medical equipment manufactures. They need to evaluate suppliers with improving technology and severe standards for changing medical requirements. Besides, increasing awareness of environment protection can't be ignored. Therefore, this study takes environment factors and medical standards into consideration, and using ANP to analyze the inside relationship of evaluation criteria and fuzzy TOPSIS to evaluate suppliers. A case study is proposed for supplier evaluation in a medical manufacture.
\end{abstract}

Keywords: ANP, fuzzy TOPSIS, supplier evaluation, medical equipment, Super Decision.

\section{Introduction}

Increasing demand of medical equipment makes it become one of the world's fastest developing industries. According to the EU Medical Device Commission statistics, the global medical device market has risen rapidly from $\$ 187$ billion in 2001 to nearly $\$ 537.2$ billion in 2014. Rich resources and huge market potential attract increasing manufactures to produce and improve their medical equipment or its parts. As special and severe requirements in medical industry and increasing awareness among people of protecting environment, how to select suppliers for hospital or manufactures becomes a popular research. For this reason, this study proposes an evaluation model considering both environmental factors and special requirements of medical industry.

Research on supplier evaluation mainly focus on criteria determination and method application. For the evaluation criteria, lots of learners have researched on its formation and it remains to consolidated and complemented. There are various approach for supplier evaluation, such as ANP (Saaty, 1996), analytic hierarchy process (AHP) (Sevkli, et al, 2007), data envelopment analysis (DEA) (Wu,2009), fuzzy TOPSIS (Yong, 2006). These approaches are workable for discovering the inside relationship of the problem, thus, this study combines the ANP and fuzzy TOPSIS to discover relationship among criteria and select the ideal suppliers.

The organization of the paper is as follow: A brief literature review about evaluation criteria and approach is discussed in Section 2; Section 3 describes the details of proposed evaluation framework. Brief computational steps of the integrated framework and the numerical calculations and analyzes are addressed in Section 4. The conclusion are shown in the final section. 
ISAHP Article: A Style Guide for Paper Proposals To Be Submitted to the International Symposium on the Analytic Hierarchy Process 2018, Hong Kong, HK.

\section{Literature Review}

Supplier evaluation is actually a multi-criteria decision-making problem including qualitative criteria and quantitative analysis. Many learners have widely research in this filed and mainly focus on criteria system determination and evaluation approach.

Research on evaluation criteria originated from America, G. W. Dickson(1966) firstly identified 23 criteria for supplier evaluation and the quality, on-time delivery, and performance history are noted as the most significant criteria. Kuo R J and Lin Y J (2012) from the view of green supply chain, proposed environment factors such as green degree of product, waste treatment, etc. Weber et al. (1991) concluded that price, delivery, quality, and production facility and location are the most frequently employed criteria, based on 74 papers.

Combination of quantitative analysis and qualitative analysis method is widely used in supplier selection problem. Sanayei A et al (2010) proposed multi-objective decision method to deal with the problem of supplier evaluation in supply chain system based on fuzzy set theory and hierarchical VIKOR model. Felix T. S. et al (2008) presented a comprehensive fuzzy TOPSIS technology to solve the problem of supplier selection. Tavana M et al (2017) provides a novel integrated multi-criteria decision-making approach to sustainable supplier selection problems and solve it by combining analytic network process and quality function deployment.

Based on the literature review, the present research of supplier evaluation on medical is not adequate. Criteria for evaluating healthcare equipment supplier is not reasonable, and didn't take environmental factors and medical standards into consideration. Based on the literature, this paper recognizes the criteria and solve the supplier evaluation problem using ANP and TPSIS method.

\section{Proposed medical equi pment supplier evaluation framework}

This paper proposed a novel hybrid approach based on ANP and TOPSIS methodologies to assist in medical equipment supplier decisions. Based on the methodologies, we firstly identify the medical equipment supplier evaluation criteria, and then define the weight of each criteria and finally determine the ranking of the suppliers.

3.1 Proposed methodologies for the medical equipment supplier evaluation framework As is known to all, ANP is a general form of the analytical hierarchy process first introduced by Saaty(1996), which canhandle the interdependence of elements by obtaining the composite weights of the criteria.

TOPSIS is a multicriteria decision approach identifying the ideal solution based on define the positive ideal solution and the negative ideal solution, while the ideal solution has the shortest distance from the positive ideal solution and the farthest distance from the negative ideal solution. Human judgements are always imprecise and subjective, therefore, evaluations are expressed by linguistic terms and convert to fuzzy numbers.

3.2 Criteria of healthcare equipment supplier framework

After a detailed literature research and expert opinions collection about the medical equipment supplier, some elements are founded to assist in supplier selection as the foundation of the evaluation framework. They are listed as below:

Product dimension: Major elements of the product dimension typically include: price, service, on-time delivery and green degree. Price usually is the typical factor influence customers choice, and the hospital is not the exception, while it doesn't have such great 
influence as it does in other felids. Service and the price are common elements when considering which supplier to select, including pre and after sale service, maintenance response time and technical train service. For a hospital, time always means life, so timely delivery is vital for hospital to operate and patient to be treated. With the development of society, awareness of environment protection becomes greater, thus, this paper introduce green degree of product in criteria, measuring the waste disposal and waste product treatment.

Organization of supplier dimension: For equipment suppliers of the hospital, various requirements is listed for the organization. Major five elements are: reputation, credibility, technology and R\&D ability, qualification and financial performance. Reputation influence the supplier's product quality, market influence and other factors, it is one aspect of supplier performance. Credibility assist in evaluating the stable relationship between hospital and suppliers. Technology influences hospital's performance and will have great help for doctors. Qualification ensures essential license of suppliers, such as business license and medical instrument product registration certificate. There is no doubt that financial position of the supplier is fundamental for the operation of the suppliers.

Quality dimension: Three major elements are safety, reliability and ISO13485. For the special requirements of the hospital, safety and reliability of the equipment is of great importance. The product of suppliers must have safetymonitoring system to assure that the product is safe and the result it provides is reliable. ISO13485 is medical equipment quality management system to guarantee the equipment quality for health and safety of people.

Relationship with partner dimension: Cooperative research and relationship management are two elements that influence the cooperation between hospital and its suppliers. Cooperative research between supplier firms and hospital will benefit both of them on product competitiveness and practicality. Relationship management is a factor influences constant cooperation with supplier firms on sharing true information and communicating ability. Fig. 1 presents the network structure of the evaluation framework.

\section{Case study}

G company is a large medical equipment manufacturer mainly producing X-Ray, CT, etc. Now, it searches for new suppliers with high technology to improve its equipment. After preliminary screening, there are five suppliers left. The company hopes to select the most competitive one, so our ANP-fuzzy TOPSIS method is used to evaluate suppliers. 6 managers and 12 quality engineers are selected to join the evaluation process. Here are computational steps of the integrated framework:

Step 1: Determination of the evaluation model. Decision goal is evaluating and selecting suppliers for $\mathrm{G}$ company including determinating the sets of criteria discussed in Section 3.2 and the weights of criteria.

Step 2: Determinating weights for criteria using ANP. The computation of this step can be conducted by Super Decision. Fig. 1.

Step 2.1: Constructing the framework of evaluation model in Super Decision. See in

Step 2.2: Establishing the pair wise comparison in each level and conducted with respect to their relative importance towards their control criterion. The preference of each pair elements of the decision maker is given by the experts in $\mathrm{G}$ company using figure from 1 to 9 . The greater the number, the stronger the importance.

Step 2.3: Forming a supermatrix and solve it to obtain the weight of the criteria. Fig. 2 shows the result. 
Step 3: Evaluating the alternatives by using fuzzy TOPSIS.

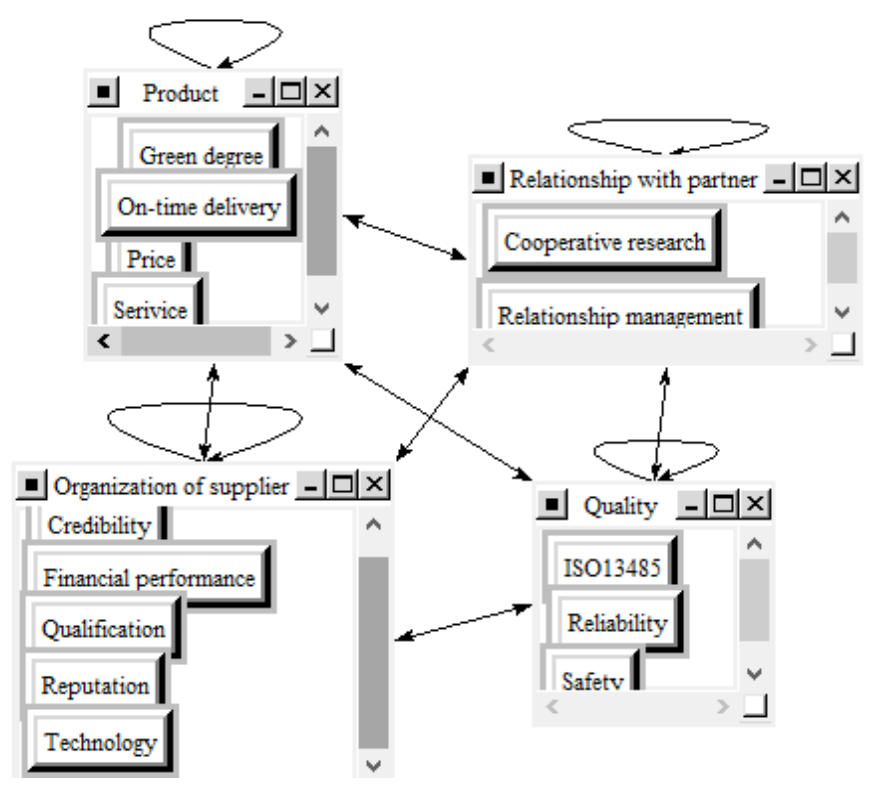

Fig. 1 Network structure of the evaluation framework

Table 1 The final ranking of the criteria.

\begin{tabular}{l|c|c|c|c|c}
\hline Supplier & S1 & S2 & S3 & S4 & S5 \\
\hline Performance index & 0.2540 & 0.2176 & 0.4611 & 0.1011 & 0.2613 \\
\hline
\end{tabular}

\begin{tabular}{|c|c|c|}
\hline \multicolumn{3}{|c|}{ Here are the priorities. } \\
\hline Name & $\longdiv { \text { Normalized by Cluster } }$ & $\longdiv { \text { Limiting } }$ \\
\hline Reputation & 0.26290 & 0.053235 \\
\hline Credibility & 0.57705 & 0.116845 \\
\hline Technology & 0.11493 & 0.023272 \\
\hline Qualification & 0.02107 & 0.004267 \\
\hline Financial performance & 0.02405 & 0.004869 \\
\hline Safety & 0.44042 & 0.128520 \\
\hline Reliability & 0.54241 & 0.158283 \\
\hline ISO13485 & 0.01717 & 0.005009 \\
\hline Cooperative research & 0.43695 & 0.094167 \\
\hline Relationship management & 0.56305 & 0.121345 \\
\hline Price & 0.59478 & 0.172598 \\
\hline Serivice & 0.11676 & 0.033882 \\
\hline On-time delivery & 0.06936 & 0.020127 \\
\hline Green degree & 0.21911 & 0.063582 \\
\hline
\end{tabular}

Fig. 2 The weight of the criteria.

Step 3.1: Establishing fuzzy decision matrix for evaluation of the medical equipment supplier. 
ISAHP Article: A Style Guide for Paper Proposals To Be Submitted to the International Symposium on the Analytic Hierarchy Process 2018, Hong Kong, HK.

Step 3.2: Normalize the decision matrix.

Step 3.3: Computing weighted decision matrix. points.

Step 3.4: Computing the distance of alternatives from the positive and negative ideal

Step 3.5: Ranking the alternatives. Table 1 shows the final ranking, and the best suppliers is $\mathrm{S} 3$ with a score of 0.4611 .

\section{Conclusions}

This paper proposes a hybrid multi-criteria decision-making approach for medical equipment supplier evaluation problem. Based on the literature review and expert opinions, medical equipment supplier evaluation criteria system is defined and ANP-fuzzy TOPSIS evaluation model is formulated. The proposed model was implemented in the G company in case study which showed the scientificity and practicability of the model.

Taking environment factors and hospital condition into consideration, our evaluating criteria is practicable applied to medical supplier selection. The combined ANP and fuzzy TOPSIS offered accurate and efficient analysis for supplier selection. As the model is novel, it can be improved in both criteria determination and methodology with the development of the medical supplier selection research.

\section{Key References}

Awasthi A, Govindan K, Gold S. Multi-tier sustainable global supplier selection using a fuzzy AHP-VIKOR based approach[J]. International Journal of Production Economics, 2017, 195:106-117.

Dickson GW. An analysis of vendor selection systems and decision[C]// Materials Science Forum. 1996:1377-1382.

Felix T. S. Chan, N. Kumar, M. K. Tiwari, et al. Global supplier selection: A fuzzy-AHP approach[J]. International Journal of Production Research, 2008, 46(14):3825-3857.

R.J.Kuo, Y.J. Lin. Supplier selection using analytic network process and data envelopment analysis[J]. International Journal of Production Research, 2012, 50(11):2852-2863.

Saaty, T.L. (1996). Decision Making with Dependence and Feedback: The Analytic Network Process. RWS Publisher[J].

Sanayei A, Mousavi S F, Yazdankhah A. Group decision making process for supplier selection with VIKOR under fuzzy environment[J]. Expert Systems with Applications, 2010, 37(1):24-30.

Weber C A, Current J R, Benton W C. Vendor selection criteria and methods[J]. European Journal of Operational Research, 1991, 50(1):2-18.

Yong D. (2006). Plant location selection based on fuzzy TOPSIS[J]. International Journal of Advanced Manufacturing Technology, 28(7-8):839-844. 